\title{
Togitare
}

RELATO DE EXPERIÊNCIA

\section{FORMAÇÃO DOCENTE PARA O ENSINO DA EDUCAÇÃO INTERPROFISSIONAL}

\author{
Elaine Andrade Leal Silva ${ }^{1}$ \\ Gilberto Tadeu Reis da Silva ${ }^{2}$ (1) \\ Nívia Vanessa Carneiro dos Santos ${ }^{2}$ (1) \\ Rosana Maria de Oliveira Silva ${ }^{2}$ (1) \\ Fernanda Moreira Ribeiro Fraga ${ }^{2}$ () \\ Juliana Costa Ribeiro-Barbosa ${ }^{2}$ (1) \\ Bruna Costa Leal ${ }^{3}$ (i)
}

\begin{abstract}
RESUMO
Objetivo: relatar experiências das autoras em relação à formação docente para o ensino da Educação Interprofissional.

Desenvolvimento: relato de experiência a partir da observação direta das atividades de docentes de duas universidades públicas do estado da Bahia, entre 2014 e 2019. Os dados foram registrados em diário de campo, organizados por aproximação temática e analisados em suas partes e nas relações entre a formação docente e o ensino da Educação Interprofissional. Identificou-se três dimensões: inquietações e reflexões nos campos práticos; movimento de aproximação ao ensino da Educação Interprofissional; e movimento na pós-graduação.

Conclusão: as experiências vividas na formação docente contribuíram para o ensino, tendo em vista a Educação Interprofissional, por suscitarem reflexões sobre os movimentos formativos do docente em direção à interprofissionalidade e constatações acerca das possibilidades formativas do docente. Espera-se que tais experiências sejam continuadas e aplicadas nos diferentes espaços de ensino.
\end{abstract}

DESCRITORES: Ensino; Docentes; Educação Interprofissional; Saúde; Educação superior.

\section{FORMACIÓN DOCENTE PARA LA ENSEÑANZA DE LA EDUCACIÓN INTERPROFESIONAL}

\section{RESUMEN:}

Objetivo: relatar experiencias de las autoras en lo que se refiere a la formación docente para la enseñanza de la Educación Interprofesional. Desarrollo: relato de experiencia a partir de la observación directa de las actividades de docentes de dos universidades públicas del estado de Bahía, entre 2014 y 2019. Los datos se registraron en un diario de campo, se organizaron por enfoque temático y se analizaron en sus partes y en las relaciones entre la formación docente y la enseñanza de la Educación Interprofesional. Se identificaron tres dimensiones: preocupaciones y reflexiones en los ámbitos prácticos; movimiento para abordar la enseñanza de la Educación Interprofesional; y movimiento en la formación de postgrado. Conclusión: las experiencias vividas en la formación docente han contribuido a la enseñanza, con vistas a la Educación Interprofesional, haciendo suscitar reflexiones sobre los movimientos formativos del docente hacia la interprofesionalidad y hallazgos sobre las posibilidades formativas del docente. Se espera que estas experiencias tengan continuidad y se apliquen en los diferentes espacios de enseñanza.

DESCRIPTORES: Enseñanza; Docentes; Educación Interprofesional; Salud; Educación superior. 
A formação docente para o ensino interprofissional assume um papel importante no movimento de mudança curricular no ensino em saúde, por estimular reflexões sobre o ensino-aprendizagem e inovações educacionais. Nesta direção, é necessário o desenvolvimento de programas de qualificação docente e o incentivo de espaços dialógicos entre professores e profissionais de saúde, que poderá impactar na promoção de mudanças no ensino em saúde ${ }^{(1)}$.

A Educação Interprofissional consiste em um modelo educacional no qual estudantes de duas ou mais profissões aprendem uns com os outros, sobre o outro, para garantir um cuidado seguro(2). Sob este referencial teórico, o currículo interprofissional requer dos docentes um ensino que valorize os processos interativos, concilie expectativas, promova interatividade, suscite reflexões, utilize tecnologia baseada na prática e propicie a retroalimentação na prestação de cuidado e a resolução de problemas centrados no cliente.

Assim, faz-se necessário um preparo prévio didático-pedagógico do professor ${ }^{(3)}$, tendo em vista as mudanças paradigmáticas no âmbito da formação em saúde, as constantes inovações educacionais e as transformações curriculares e metodológicas, incluindo tecnologias de informação e comunicação(4).

No entanto, apesar da relevância desta formação em consonância com o atual contexto do ensino em saúde, há lacuna de estudos que abordem a formação docente, bem como a interação entre esta e a Educação Interprofissional em Saúde (ÉIP)(5). Tornase pertinente o presente artigo, visto que o relato de uma experiência sobre formação docente possivelmente subsidiará reflexões a respeito do movimento formativo e fomentará experiências semelhantes a outros pares. Portanto, estabeleceu-se como objetivo relatar as experiências das autoras em relação à formação docente para o ensino da EIP.

\section{DESENVOLVIMENTO}

Trata-se de um relato de experiência sobre a formação docente para o ensino da educação interprofissional, realizado a partir da observação direta ativa das atividades de ensino, pesquisa e extensão desenvolvidas por docentes de duas universidades públicas da Bahia, no período de março de 2014 a junho de 2019.

Os dados da observação foram registrados em um diário de campo, sob forma de apontamentos, portfólios reflexivos e minutas de reunião, e então organizados por aproximação temática e analisados em suas partes e nas relações entre a formação docente para o ensino da Educação Interprofissional.

Por se tratar de um relato de experiência exclusivamente dos docentes que são autores deste manuscrito, sem possibilidade de identificação individual, não foi necessário aplicar o Termo de Consentimento Livre e Esclarecido e o estudo não necessitou ser registrado/avaliado por Comitê de Ética em Pesquisa. Garantiu-se a confidencialidade dos participantes e resguardou-se o sigilo das informações fornecidas em confiança, tal como preconizado pelas Resoluções 466/12 e 510/16 do Conselho Nacional de Saúde.

Para melhor visualização dos resultados, a experiência foi dividida em três momentos formativos: Inquietações e reflexões nos campos de práticas, Movimento de aproximação ao ensino da ElP, e Movimento na pós-graduação. Ressalta-se que o pensar analítico deste relato foi baseado no processo de ação-reflexão-ação(6), delineando um caminho para 
formação docente para o ensino da EIP.

\section{Inquietações e reflexões nos campos de prática}

Foram constatadas a inexistência de planejamento participativo e integrado entre docentes de diferentes cursos que atuam nos serviços de saúde e a ausência de atividades conjuntas entre docentes, suscitando inquietações a respeito da formação docente ser ou não adequada para a atuação no Sistema Único de Saúde (SUS).

Nessa perspectiva, emanaram reflexões acerca da (in)existência de espaços dialógicos nas universidades capazes de potencializar o desenvolvimento do trabalho colaborativo.

As diferentes possibilidades de ação-reflexão-ação para formação docente no ensino da EIP procederam das rodas de conversa, leituras programadas, construção de plano de curso e reflexões com o núcleo docente estruturante do curso de graduação em enfermagem. Estas possibilidades propiciaram o desenvolvimento de habilidades e competências para o fazer docente a serem aplicadas em diferentes contextos, como no tirocínio docente, estágio docente, sala de aula e espaços afins.

A formação docente, na perspectiva da EIP, é apreendida no ensinar e nas reflexões advindas das experiências, da construção do saber e dos projetos coletivos ${ }^{(7)}$. Também envolve o compromisso docente com a EIP e com o desenvolvimento de competências relacionadas à flexibilidade no trabalhar com o outro, criatividade de construir experiências de aprendizagem colaborativa e intencionalidade para trabalharem grupo interprofissional ${ }^{(8)}$.

\section{Movimento de aproximação ao ensino da Educação Interprofissional}

O movimento de aproximação ao ensino da EIP ocorreu de diversas formas, entre elas: encontros institucionais nos espaços de integração ensino-serviço e de reuniões; encontros pedagógicos; planejamento integrado entre diferentes áreas acadêmicas; aulas com professores de diversas formações; elaboração de projetos de pesquisa e formação de grupos de estudo com membros de vários cursos da saúde.

Ao longo desta jornada de formação, destacou-se uma experiência desenvolvida por uma das autoras nos cenários de prática e no planejamento e promoção de ações propositivas para o trabalho interprofissional.

As informações oriundas do diário de campo sobre as práticas curriculares uniprofissionais permitiram que alguns docentes vislumbrassem a possiblidade de permear entre os diversos campos do saber, de modo a valorizar uma formação que dialogasse com os profissionais dos diferentes cursos de saúde envolvidos, bem como o desenvolvimento da escuta e interdependência entre os pares.

Programas extensionistas e de educação para o trabalho são potencializadores para integrar as instituições de ensino superior a comunidades e serviços de saúde, de modo a promover a transição da formação uniprofissional para a interprofissional( ${ }^{(9)}$. Nessa perspectiva, o processo de formação docente deverá ser permanentemente compartilhado com outros pares, por meio de artigos científicos, simpósios, seminários e reuniões, por exemplo.

\section{Movimento na pós-graduação}

Outro movimento observado para qualificar a formação docente no âmbito strictu ou latu senso foi o estímulo de um Programa de Pós-Graduação em Enfermagem e Saúde de uma universidade pública da Bahia. Este programa oferta atividades e componentes curriculares que incluem estágio em docência, formação didático-pedagógica e tirocínio docente orientado. 
Pode-se citar como exemplo deste programa a presença do componente curricular FormaçãoDidático-Pedagógica em Saúdee Enfermagem, o qual sefundamentana concepção filosófica de formar profissionais capazes de desenvolver práticas transformadoras. Neste caso, o foco reside em formar docentes e, para tanto, foram disponibilizados diversos horários e tipos de encontros, para que fossem flexíveis e pudessem incluir, além dos discentes do programa de pós-graduação, trabalhadores e docentes da área da saúde, das redes pública e privada.

Particularmentenoâmbitodapós-graduação, estemovimento apresentapossibilidades por meio do desenvolvimento de projetos, mestrado e/ou doutorado interinstitucional, onde os docentes podem realizar pesquisas relacionadas à formação docente para a EIP e, sobretudo, vivenciar a prática do ensino da EIP em pesquisas integradas, atividades assistenciais de cuidados humanos, tirocínio docente e eventos científicos.

Aliado a isto, a literatura aponta para a necessidade de formar docentes ao longo da sua prática, por meio de programas de pós-graduação que qualifiquem o docente para o ensino da EIP(5). Neste interim, a proposta de incluir matrícula como aluno especial, ou componente optativo a trabalhadores de saúde, docentes de instituições públicas e privadas, representa um avanço em direção à formação docente. Processo este vivido pelas autoras deste relato, que experienciaram um percurso formativo e um alinhamento com os fundamentos teóricos acerca da docência em saúde.

A partir do supracitado, observa-se que há pujantes possibilidades para que os programas de pós-graduação invistam na formação docente para a EIP, e considera-se que esta tenha sido uma experiência exitosa, uma vez que permitiu aos envolvidos a elucubração de diferentes movimentos para a formação docente em prol do ensino da EIP.

\section{CONSIDERAÇÕES FINAIS}

A experiência docente relatada neste artigo foi permeada por inquietações e reflexões nos campos de práticas a respeito da EIP, do movimento de aproximação a esta modalidade de ensino e das possibilidades de fomentá-la durante a pós-graduação. Observou-se que tal formação poderá ser potencializada mediante a oferta e continuidade de movimentos formativos presentes no cotidiano do trabalho docente.

No entanto, é necessário que docentes de diferentes cursos dialoguem e, juntos, planejem ações e práticas interprofissionais. Neste relato, ficou evidente que as experiências contribuíram para a formação docente por suscitarem reflexões sobre os movimentos formativos do docente em direção à interprofissionalidade e constatações acerca das possibilidades formativas do docente, bem como projeções para o futuro da graduação e pós-graduação.

Recomenda-se o desenvolvimento de novos estudos que permitam ampliar o conhecimento sobre a experiência de diagnosticar-intervir acerca de algumas práticas de ensino, de maneira que outros docentes de diferentes profissões de saúde se percebam e movimentem-se em direção a uma educação interprofissional.

Como principal desafio, assinala-se a dificuldade do docente em se perceber no processo formativo, ação-reflexão-ação, para o ensino da EIP. Conclui-se que as experiências vividas na formação docente para a ensino da EIP devem ser continuadas e aplicadas nos diferentes espaços que integram o ensino e os serviços de saúde. 
Ao apoio da Coordenação de Aperfeiçoamento de Pessoal de Nível Superior - Brasil (CAPES) código 001. Ao CNPq referente à Bolsa de Produtividade em Pesquisa (PQ), sob o $n^{\circ}$ do processo 307977/2018-8 e a Bolsa de Pós-doutorado no Exterior através do processo CNPq: 205736/2018-1.

\section{REFERÊNCIAS}

1. Silva GTR da. Interprofessional education and faculty training in health. Rev. Enf. Ref. [Internet]. 2020 [acesso em 26 mar 2019]; 5(1). Disponível em: http://ciberindex.com/index.php/ref/article/ view/5202011p/5202011p.

2. Reeves S, Fletcher S, Barr H, Birch I, Boet S, Davies N, et al. A BEME systematic review of the effects of interprofessional education: BEME Guide No. 39. Med Teach [Internet]. 2016 [acesso em 26 mar 2019]; 38(7). Disponível em: https://doi.org/10.3109/0142159X.2016.1173663.

3. Peres $A M$, Rocha JR, Caveião $C$, Hipolito $A C L$, Mantovani $M$ de F. Estratégias de ensino na graduação em enfermagem: estudo descritivo. Cogitare enferm. [Internet]. 2018 [acesso em 05 jun 2019]; 23(4). Disponível em: http://dx.doi.org/10.5380/ce.v23i4.55543.

4. Batista NA, Rossit RAS, Batista SHS da S, Silva CCB da, Uchôa-Figueiredo L da R, Poletto PR. Educação interprofissional na formação em Saúde: a experiência da Universidade Federal de São Paulo, campus Baixada Santista, Santos, Brasil. Interface (Botucatu) [Internet]. 2018 [acesso em 05 jun 2019]; 22(suppl 2). Disponível em: https://doi.org/10.1590/1807-57622017.0693.

5. Paulin JFV, Miskulin RGS. Formação de professores a distância: uma análise dos processos de ensino e de aprendizagem da matemática. Rev Educ Matemática. [Internet]. 2019 [acesso em 05 jun 2019]; 16(22). Disponível em: https://www.revistasbemsp.com.br/index.php/REMat-SP/article/view/157/pdf.

6. Freitas MA de O, Demarchi GS dos S, Rossit RAS. Educação interprofissional na pós-graduação stricto sensu: o olhar dos egressos. Interface (Botucatu) [Internet]. 2018 [acesso em 05 jun 2019]; 22(suppl2). Disponível em: https://doi.org/10.1590/1807-57622017.0644.

7. Prado ML do, Velho MB, Espíndola DS, Sobrinho SH, Backes VMS. Arco de Charles Maguerez: refletindo estratégias de metodologia ativa na formação de profissionais de saúde. Esc Anna Nery. [Internet]. 2012 [acesso em 08 maio 2020]; 16(1). Disponível em: https://www.scielo.br/pdf/ean/v16n1/ v16n1a23.pdf.

8. Reeves S. Porque precisamos da educação interprofissional para um cuidado efetivo e seguro. Interface Commun Heal Educ. [Internet]. 2016 [acesso em 15 set 2020]; 20(56). Disponível em: http://doi. org/10.1590/1807-57622014.0092.

9. Costa MV da, Patrício KP, Câmara AMCS, Azevedo GD, Batista SHS da S. Pró-Saúde e PET-Saúde como espaços de educação interprofissional. Interface (Botucatu). [Internet]. 2015 [acesso em 09 jul 2019]; 19(suppl1). Disponível em: https://doi.org/10.1590/1807-57622014.0994. 
COMO REFERENCIAR ESTE ARTIGO:

Silva EAL, Santos NVC dos, Silva GTR da, Silva RM de O, Fraga FMR, Ribeiro-Barbosa JC, et al. Formação docente para o ensino da educação interprofissional. Cogitare enferm. [Internet]. 2021 [acesso em "colocar data de acesso, dia, mês abreviado e ano"]; 26. Disponível em: http://dx.doi.org/10.5380/ce.v26i0.73871.

Recebido em: 19/05/2020

Aprovado em: 23/09/2020

Editora associada: Susanne Elero Betiolli

Autor Correspondente:

Nívia Vanessa Carneiro dos Santos

Universidade Federal da Bahia - Salvador, BA, Brasil

E-mail: nivia_vanessa@hotmail.com

Contribuição dos autores:

Contribuições substanciais para a concepção ou desenho do estudo; ou a aquisição, análise ou interpretação de dados do estudo - EALS, NVCS, GTRS, RMOS, FMRF, JCRB, BCL

Elaboração e revisão crítica do conteúdo intelectual do estudo - EALS, NVCS, FMRF

Aprovação da versão final do estudo a ser publicado - NVCS, GTRS, RMOS, FMRF, JCRB, BCL

Copyright $\odot 2021$ Este é um artigo em acesso aberto distribuído nos termos da Licença Creative Commons Atribuição, que permite o uso irrestrito, a distribuição e reprodução em qualquer meio desde que o artigo original seja devidamente citado. 